NASA Technical Memorandum 102013

\title{
Gas Density Effect on Dropsize of Simulated Fuel Sprays
}
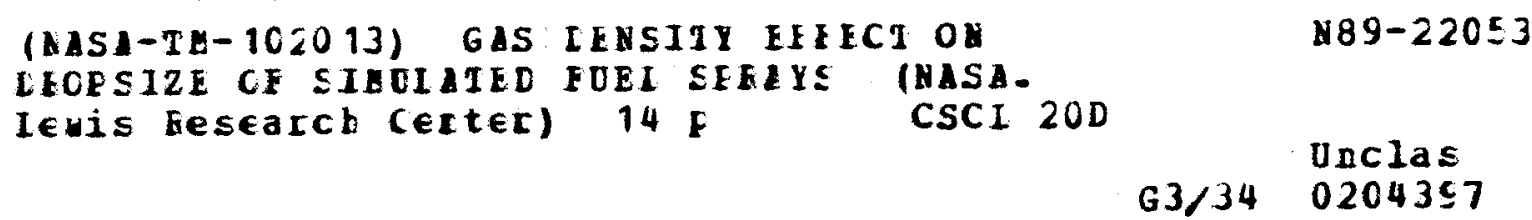

Robert D. Ingebo

Lewis Research Center

Cleveland, Ohio

Prepared for the

25th Joint Propulsion Conference

cosponsored by the AIAA, ASME, SAE, and ASEE

Monterey, California, July 10-12, 1989 


\author{
Robert $D$. Ingebo \\ National Aeronautics and Space Administration \\ Lewis Research Center \\ Cleveland, Ohio 44135
}

\section{Abstract}

Two-phase flow in pneumatic two-fluid fuel nozzles was experimentally investigated to determine the effect of atomlzing-gas density and gas massflux on liquid-jet breakup in sonic-velocity gasflow. Dropsize data were obtained for the following atomizing-gases: nitrogen, argon, carbon dioxide $\underset{N}{\sim}$ and helium. They were selected to cover a gas i molecular-weight range of 4 to 44 . Atomizing-gas mass-flux ranged from 6 to $50 \mathrm{~g} / \mathrm{cm}^{2}-\mathrm{sec}$ and four differently sized two-fluid fuel nozzles were used having orifice diameters that varied from 0.32 to $0.56 \mathrm{~cm}$.

The ratio of liquid-jet diameter to $S M D, D_{0} / D_{32}$. was correlated with aerodynamic and liquid-surface forces based on the product of the Weber and Reynolds number. We Re, and gas-to-liquid density ratio.

$\rho g / p l$. To correlate spray dropsize with breakup forces produced by using different atomizing-gases, a new molecular-scale dimensionless group was derived, $\rho_{1} v_{m}^{3} / g \mu_{g}$, and used to obtain the following expression:

$$
D_{0} 10_{32}=4.33 \times 10^{-11}\left(\text { We Re } \rho_{g} / \rho_{1}\right)^{0.44}\left(\rho_{1} v_{m}^{3} / g \mu_{g}\right)^{0.75}
$$

where We $R e=\rho_{g}^{2} D_{0}^{2} v_{c}^{3} / \sigma \mu_{1}, \mu_{1}$ is liquid viscosity, $\sigma$ is surface tension. $V_{c}$ is acoustic gas velocity, $V_{m}$ is RMS velocity of gas molecules, $g$ is acceleration of gas molecules due to gravity, and $\mu_{g}$ is gas viscosity.

From this expression for liquid-jet breakup in two-fluid atomizers, it is evident that $D_{32}^{-1} \sim\left(\rho_{g} V_{c}\right)^{1.33}$. This expression agrees well with atomization theory for liquid-jet breakup in highvelocity gasflow, i.e., in the regime of aerodynamic stripping. Also, it was found that at the same gas mass-flux, $p_{g} V_{c}$, helium was considerably more effective than nitrogen in producing smalldroplet sprays with SMD's in the order of $5 \mathrm{\mu m}$.

\section{Nomenclature}

b

dropsize parameter in Nukiyama-Tanasawa expression, cm

c dropsize parameter in Rosin-Rammler expression, $\mathrm{cm}$

DC characteristic drop dlaneter measured for entire spray, cm

Di diameter of ith drop, cm

Dv. 5 volume median drop diameter, cm

$D_{31}$ volume-linear mean drop diameter,

$$
\left[\sum_{i} \mathrm{nO}_{i}^{3} / \sum_{i} \mathrm{nD}_{i}\right]^{0.5}
$$

\author{
$\mathrm{D}_{32}$ Sauter mean drop diameter,$$
\sum_{i} \mathrm{no}_{\mathrm{i}}^{3} / \sum_{\mathrm{i}} \mathrm{nD}_{\mathrm{i}}^{2}, \mathrm{~cm}
$$ \\ k correlation coefflclent for Eq. (1) \\ k' correlation coefficient for Eq. (3) \\ $N_{n}$ exponent for Nukiyama-Tanasawa dropsize dis- \\ tribution expression \\ $\mathrm{Nr}_{r}$ exponent for Rosin-Rammler dropsize distribu- \\ tion expression \\ number of droplets \\ gas constant, $8.31 \times 10^{7}$ ergs \\ Reynolds number, $D_{O P g} V_{c} / \mu$ \\ fluid velocity, $\mathrm{cm} / \mathrm{sec}$ \\ volume fraction of droplets with diameters \\ less than or equal to $x$ \\ weight flow of fluid, g/sec \\ Weber number, $D_{0} \rho_{g} v_{c}^{2} / \sigma$ \\ droplet diameter in dropsize distribution \\ expression, cm \\ $\mu \quad$ absolute viscosity, $\mathrm{g} / \mathrm{cm} \mathrm{sec}$ \\ $\rho$ fluid density, $\mathrm{g} / \mathrm{cm}^{3}$ \\ $\sigma$ surface tension of liquid relative to air. \\ dynes/cm

\section{Subscripts:} \\ c acoustic \\ g gas \\ 1 liquid \\ m molecular \\ orifice \\ water
}

\section{Introduction}

Liquid-fueled gas turbine and rocket combustor performance can be markedly improved with two-fluid fuel nozzles capable of producing large numbers of small fuel droplets, i.e., fuel sprays that have a large liquid surface-area to volume ratio. This improvement in combustor performance is due to the fact that large surface-area sprays yield high vaporization and burning rates. The very small droplets produced by this type of atomizer vaporize 
fast enough so that it may also be used to form premixed-prevaporized fuel-air mixtures suitable for application in catalytic combustors.

As reported in Ref. 1, an investigation was previously conducted using four differently sized two-fluid nozzles. It was found that reciprocal Sauter mean diameter, $\mathrm{O}_{32}^{-1}$, could be correlated with the product of the Weber number, Reynolds number, and gas-to-liquid density ratio raised to the 0.44 power as follows: $D_{32}^{-1} \sim\left(\text { we } \operatorname{Re} \rho_{g} / \rho_{1}\right)^{0.44}$. This relationship shows that $D_{32} \sim v_{c}^{-1.33}$ where $v_{c}$ is acoustic gas velocity. The exponent agrees with that predicted by atomization theory for liquid-jet breakup in high velocity gasflow.

Numerous investigators have studied the effect of fluid properties on liquid-jet atomization. Some of their results are given in Refs. 2 to 4 . Of all the fluid properties that affect atomization, it was found in Ref. 1, that acoustic mass-flux, $\rho_{g} V_{c}$, had the greatest effect on the fineness of atomization obtained with two-fluid nozzles. However at present, the independent effect of gas density, pg, on spray dropsize has not been very well established in the literature as indicated in Refs. 5 and 6 . Therefore, in the present study, the effect of gas density on spray dropsize was investigated. To accomplish this, acoustic gas-velocity was held constant while gas density was varied. In addition, a wide range of acoustic gas-velocities was investigated by using four different atomizing gases having molecular weights ranging from 4 to 44 . The gases used were helium, nitrogen, argon and carbon dioxide.

In the present study, two-phase flow in fuel nozzles was experimentally investigated to determine the effect of acoustic gas-velocity and massflux on characteristic spray dropsizes produced by liquid-jet breakup in high velocity gasflow. Characteristic dropsizes were measured with a scatteredlight scanner developed at the NASA Lewis Research Center. 7 The sprays were sampled at a distance of $2.2 \mathrm{~cm}$ downstream of the fuel-nozzle orifice, to minimize the loss of small droplets due to vaporization and dispersion. The sprays were injected into a low velocity, $5 \mathrm{~m} / \mathrm{sec}$, stream to aid in transporting very small droplets through the laser beam. Small-droplet sprays with Sauter mean diameters varying from 3 to $30 \mu \mathrm{m}$ were produced by the atomization of small-diameter liquid jets in the regime of aerodynamic-stripping. i.e., high-velocity gasflow. Liquid and gas pressures were varied from 0.2 to $1.0 \mathrm{MPa}$.

\section{Apparatus and Procedure}

A two-fluid atomizer was mounted horizontally in the open duct as shown in Fig. 1. Air supplied at ambient temperature. $293 \mathrm{~K}$, passed through the $24 \mathrm{~cm}$ inside diameter test section before being exhausted to the atmosphere. The test section was $1 \mathrm{~m}$ in length and airflow rate in the test section was measured with a $5.08 \mathrm{~cm}$ diameter orifice. To aid in transporting small droplets through the laser beam, an airstream velocity of $5 \mathrm{~m} / \mathrm{sec}$ was maintained in the test section. Figure 2 shows a schematic drawing of the spray and instrumentation.

Four pneumatic two-fluid atomizers were fabricated according to the diagram illustrated in Fig. 3 with orifice diameters ranging from 0.32 to $0.56 \mathrm{~cm}$. The atomizer was operated over pressure ranges of 0.2 to $1.0 \mathrm{MPa}$ for both water and the atomizing gas. Sprays were injected downstream into the airflow just upstream of the duct exit. The sprays were sampled at a distance of $2.2 \mathrm{~cm}$ downstream of the atomizer.

Water at a temperature of $298 \mathrm{~K}$, measured with an I.C. thermocouple, was axially injected into the airstream by gradually opening a control valve until the desired flow rate of $3.15 \mathrm{~g} / \mathrm{sec}$ was obtained as indicated by a turbine flowmeter. The atomizing gas was then turned on and weight flowrate was measured with a $0.51 \mathrm{~cm}$ diameter sharp-edge orifice. After the air, atomizing gas and water flowrates were set, the Sauter mean drop diameter was measured with the scattered-light scanner to characterize each spray. Exponents for the Rosin-Rammler and Nukiyama-Tanasawa dropsize distribution expressions were also determined using the scattered-light scanner.

The optical system of the scattered-light scanner shown in Fig. 2 consists of a laser beam expander with a spatial filter, rotating scanning slit, and a detector. Using a 4.4 by $1.9 \mathrm{~cm}$ laser beam, the instrument measures scattered light as a function of scattering angle by repeatedly sweeping a variablelength slit in the focal plane of the collecting lens. The data obtained is scattered-light energy as a function of the scattering angle relative to the laser beam axis. This method of particle size measurement is similar to that given in Ref. 8 .

In Ref. 9, it was found that measurements of points on a plot of scattered-light energy normalized to the maximum energy and plotted against scattering angle can be used to determine the Sauter mean diameter, the volume median, the volume linear and the 75-percent volume diameters as illustrated in Fig. 4. The dispersion of the size distribution is also determined from the points on the plot shown in Fig. 4. Also, it should be noted that this method of determining characteristic drop diameters and dispersion of dropsizes can be used independent of the particle size distribution function as discussed in Ref. 9. For a typical measurement, the scan is repeated 60 times per second to average out any temporal variations in the energy curve.

Spray pattern effects were minimized by measuring characteristic drop diameters using the entire spray. Reproducibility using this technique was within \pm 5 percent. Calibration was accomplished with five sets of monosized polystyrene spheres having diameters of $8,12,25,50$, and $100 \mu \mathrm{m}$. Since the present sprays were sampled very close to the atomizer orifice, they contained a relatively high number-density of very small drops. As a result, the light-scattering measurements required correction for multiple scattering as described in Ref. 10.

Drop size measurements were al so corrected to include Mie scattering theory when very small droplet diameters, i.e., <10 $\mu \mathrm{m}$, were measured.

\section{Experimental Results}

Four atomizing gases, i.e., nitrogen, argon, carbon dioxide and helium were used in two-fluid fuel nozzles to study the effect of atomizing-gas density on spray dropsize. To demonstrate this 
effect. several dimensionless groups were investigated.

Effect of Atomizing-Gas Mass-Flux on Spray Dropsize

The reciprocal SMD, $D_{32}^{-1}$ was plotted against atomizing-gas flowrate per unit area as shown in Fig. 5. From this plot, the following relationship is obtained for the four atomizing-gases, helium, nitrogen, argon and carbon dioxide:

$$
D_{32}^{-1}=k\left(w_{g} / A_{0}\right)^{1.33}
$$

where $k$ is a correlation coefficient that is a function of the gas used to atomize water jets. Equation (1) can be rewritten in terms of gas massflux as follows:

$$
D_{32}^{-1}=k\left(\rho_{g} V_{g}\right)^{1.33}
$$

Values of the correlation coefficient, $k$, for each atomizing gas are given in Tablle 1.

The four atomizing gases show good agreement with atomization theory. 1 which predicts reciproCal SMD to be directly proportional to gas velocity raised to the 1.33 power. This exponent also agrees well with the results previously reported in Ref. I and the value of 11.5 obtained for the coefficient $k$ is in good agreement with that reported in Ref. 7 for two-fluid atomizers using nitrogen gas.

A comparison of $k$ values clearly shows the marked improvement that is obtained in fineness of atomization when a low-density gas such as helium is used as the atomizing gas for two-fluid fuel nozzles operating at acoustic gas velocities. The attainment of a large liquid-surface area per unit volume of liquid, i.e., large values of reciprocal SMD. $0_{32}^{-1}$, with the use of helium is attributed to the low molecular weight and therefore high acoustic-velocity of hellum. On the other hand, the higher molecular weights and lower acoustic velocities of argon and carbon dioxide make them much less efficient as atomizing-gases for two-fluid fuel nozzles operating at acoustic gas velocities.

Correlation of Normalized Reciprocal SMD with Dimensionless Groups

In the study of liquid-jet breakup in highvelocity nitrogen gasflow that is reported in Ref. 1, it was found that the reciprocal of the normalized SMD, $\left(D_{32} / D_{0}\right)^{-1}$. could be directly correlated with the product of the Weber and Reynolds numbers, We Re, multiplled by the gas-to-liquid density ratio, $\rho_{g} / \rho_{l}$, as follows:

$$
D_{0} / D_{32}=k^{\prime}\left(\text { We } \operatorname{Re} \rho_{g} / \rho_{1}\right)^{0.44}
$$

where We Re $=D_{0}^{2} \rho_{g}^{2} V_{c}^{3} / \mu_{1} \sigma$ and $v_{c}$ is the acoustic velocity of the gas. Atomization data obtained for the four atomizing gases are shown in Fig. 6 . From the slope of the plots, a correlation coefficient $k^{\prime}$ was determined for each atomizing-gas and values of $k^{\prime}$ are recorded in Table 1 .
Effect of Atomizing-Gas Properties on Liquld-Jet Breakup

The primary objective of this investigation was to study liquid-jet breakup in two-fluid atomizers by using four different atomizing-gases and correlate reciprocal Sauter mean diameter, $\mathrm{D}_{32}^{-1}$, with atomizing-gas properties. As shown in Fig. 6, the product of the Weber and Reynolds numbers and the density ratio do not give a single correlating expression. In order to accomplish the objective of this study, the normalized reciprocal Sauter mean diameter, $D_{0} / D_{32}$, produced by liquid-jet breakup with two-fluid atomizers is also assumed to be a function of the RMS velocity of the gas molecules, $v_{m}$. the acceleration of gas molecules due to gravity, $g$, atomizing-gas viscosity, $\mu_{\mathrm{g}}$, and liquid density, $\rho l$. Using dimensional analysis, the following expressions are obtained:

$$
D_{0} / D_{32}=f\left(V_{m}, \mu_{g}, P_{1}, g\right)
$$

where $V_{m}=\sqrt{3 R T_{g}} / M_{g} \cdot 12$ By rewriting Eq. (4), there results:

$$
D_{0} / D_{32}=f\left(p_{1}\right)^{a}\left(V_{m}\right)^{b}(g)^{c}\left(\mu_{g}\right)^{d}
$$

The preceding equation is then expressed in terms of the mass-length-time system (where $T$ is time: $M$, mass; and $L$, length) to give:

$$
\frac{D_{O}}{D_{32}}=f\left(\frac{M}{L^{3}}\right)^{a}\left(\frac{L}{T}\right)^{b}\left(\frac{L}{T^{2}}\right)^{c}\left(\frac{M}{L T}\right)^{d}
$$

so that for:

$$
\begin{gathered}
M, O=a+d \\
T, 0=-b-2 c-d \\
L, 0=-3 a+b+c-d
\end{gathered}
$$

which may be written as:

$$
\begin{gathered}
a=-d \\
b=-2 c-d=-3 d \\
c=3 a-b+d
\end{gathered}
$$

Substitution of these values into Eq. (5) gives:

$$
D_{0} / D_{32}=f\left(\rho_{1} v_{m}^{3} / g_{g}\right)^{-d}
$$

To obtain a general correlating expression for the four atomizing-gases, the correlation coefficient $k^{\prime}$ is plotted against $\rho_{1} v_{m}^{3} / g \mu_{g}$. From the slope of this plot shown in Fig. 7 , the following relationship is obtained:

$$
k^{\prime} \sim\left(\rho_{1} v_{m}^{3} / g \mu_{g}\right)^{0.75}
$$


where the exponent $-d$, derived from dimensionless analysis is equal to 0.75 . Since this exponent is fairly large, the variables $\mu_{g}, \rho, V_{m}$, and $g$ have $a$ very important effect on the liquid-jet breakup process. Microgravity studies are needed in which $g$ is varied to determine if the exponent 0.75 is correct for $g$.

To obtain a single correlating coefficient for the atomizing-gases, values of $D_{0} / D_{32}$ are plotted against the product of the dimensionless groups given in Eqs. ( 3 ) and ( 8 ), as shown in Fig. 8 . Thus the following expression is obtained for the four atomizing gases:

$D_{0} / D_{32}=4.33 \times 10^{-11}\left(\text { We } \operatorname{Re} \rho_{g} / \rho_{1}\right)^{0.44}\left(\rho_{1} v_{m}^{3} / g \mu_{g}\right)^{0.75}$

Since we $\operatorname{Re}\left(\rho_{g} / \rho_{1}\right)=D_{o}^{2}\left(\rho_{g} V_{c}\right)^{3} / \mu_{1} \rho_{1} \sigma$, it is evident that the reciprocal Sauter mean diameter is proportional to $v_{m}^{2.1}, \rho_{1}^{0.31}, \mu_{g}^{-0.75}$ and gas molecular weight raised to the -0.46 power. For the liquid properties, $D_{32}^{-1}$ is proportional to $\mu_{i}^{-0.44}, \sigma^{-0.44}$ and $\rho_{1}^{0.31}$. These exponents give fairly good agreement with those predicted by atomization theory, as shown in Table 2. Therefore Eq. (9), al though it was derived for water-jet breakup, should give fairly good results in predicting fuel-jet breakup in Mach 1 gasflow with two-fluid nozzles.

Correlation of Exponents for Dropsize Distribution Expressions

The scattered-light scanner gave data for the exponent $N_{r}$, which appears in the Rosin-Rammler expression as follows: 13

$$
\frac{d v}{d x}=\frac{N_{r} x^{N_{r}-1}}{c N_{r}} e^{-(x / c)^{N_{r}}}
$$

Data were also obtained for the exponent $N_{n}$, which appears in the Nukiyama-Tanasawa expression as follows: 13

$$
\frac{d v}{d x}=\frac{b^{6 / N_{n}}}{\Gamma\left(6 / N_{n}\right)} x^{5} e^{-b x^{N_{n}}}
$$

From a plot of the data obtained with the four atomizers, as shown in Fig. 9, the following relation was determined:

$$
N_{r}=2.8 N_{n}^{0.45}
$$

which is the same as that derived in Ref. 1. Thus it was found that the relation between exponents $N_{n}$ and $N_{r}$ was not appreciably affected when the atomizing-gas molecular weight was varied from 4 to 44 .

\section{Summary of Results}

From the correlating expressions derived in this study, it is evident that:
1. The effect of atomizing-gas density, $p g$, on spray dropsize is the same as that of acoustic velocity, $v_{c}$, i.e., $\mathrm{O}_{32}^{-1} \sim\left(\rho_{g} v_{c}\right)^{1.33}$.

2. RMS gas molecular-velocity, $V_{m}$, and acoustic mass-flux, $\rho g V_{c}$, have the greatest effect of all gas- and $i$ iquid-phase properties on the process of liquid-jet breakup in high-velocity gasflow.

3. The reciprocal SMD, $\mathrm{D}_{32}^{-1}$, produced with twofluid atomizers was considerably greater for helium in comparison with nitrogen, at the same gas massflux. The superior performance of helium gas as compared with that obtained with nitrogen, is attributed to the relatively high acoustic and RMS molecular velocities of helium.

\section{Appendix - Characteristic Dropsize of Liquid Fuel- Sprays Simulated by Water-Jet Breakup in High-Velocity Gasflow}

Values of liquid properties given in Table 3 were used in Eq. (9) to calculate reciprocal Sauter mean diameters for JP-5 and n-Octane fuel-sprays. These are plotted against gas mass-flux in Fig. 10. Two sets of plots are presented. The elevation of the upper set over the lower one shows the effect on spray surface-area that is obtained, according to Eq. (9), when helium gas is used in two-fluid atomizers instead of nitrogen gas. From these plots, values of $k$ were calculated and are recorded in Table 3.

\section{References}

1. Ingebo, R.D., "Fluid Spray Simulation with Two-fluid Nozzles," AIAA Paper 89-0053, Jan. 1989. (NASA TM-101367)

2. We iss, M.A., and Worsham, C.H., "Atomization in High Velocity Airstreams," American Rocket Society Journal. Vol. 29, No. 4, Apr. 1959, pp. 252-259.

3. Wolfe, H.E, and Andersen, W.H., "Aerodynamic Breakup of Liquid Drops," Proceedings of the 5 th International Shock Tube Symposium, Z.I. Slawsky, J.F. Moulton, Jr., and W.S. Filler, Eds., Naval Ordnance Lab., White Oak, MD, 1965, pp. 1145-1169. (Avail. NTIS. AD-638011.)

4. Kim, K.Y., and Marshall, W.R., Jr., "Drop-Size Distributions from Pneumatic Atomizers, "AIChE Journal. Vol. 17, No. 3, May 1971, pp. 575-584.

5. Nukiyama, S., and Tanasawa, Y., "Experiment on Atomization of Liquid, "Iransactions of the Society of Mechanical Engineers, Japan, Vol. 5, No. 18, Feb. 1939, pp. 63-75.

6. Lorenzetto. G.E.. and Lefebvre. A.H., "Measurements of Drop-Size on a Plain-Jet Airblast Atomizer," AIAA Journal. Vol. 15. No. 7. July 1977. pp. 1006-1010.

7. Ingebo, R.O., and Buchele, O.R., "Small-Droplet Spray Measurements With a Scattered-Light Scanner," NASA TM-100973, Nov. 1988.

8. Swithenbank, J., Beer, J.M., Taylor, D.S., Abbot, D., and McCreath, G.C., "A Laser Diagnostic Technique for the Measurement of Droplet and Particle Size Distribution." AIAA Paper 76-69, Jan. 1976. 
9. Buchele, D.R., "Particle Sizing By weighted Measurements of Scattered Light," NASA TM-100968, 1988.

10. Felton. P.G., Hamidi, A.A., and Aigal, A.K., "Measurement of Drop-Size Distribution in Dense Sprays by Laser Diffraction." 3rd International Conference on Liquid Atomization and Spray Systems, ICLASS - 85, Vol. 2, $P$. Eisenklam and A. Yule, Eds.. Institute of Energy. London. 1985, pp. IVA/4/1-IVA/4/11.

TABLE 1. - CORRELATION COEFFICIENTS FOR ATOMIZING GASES:

\begin{tabular}{|c|c|c|}
\hline Atomizing-gas & \multicolumn{2}{|c|}{ Correlation coefficients } \\
\cline { 2 - 3 } & $\mathrm{k}$, Eq. (1) & $\mathrm{k}^{\prime}$, Eq. (3) \\
\hline $\mathrm{He}$ & 86.5 & 53 \\
$\mathrm{~N}_{2}$ & 11.5 & 7.5 \\
$\mathrm{Ar}$ & 6.3 & 4.0 \\
$\mathrm{CO}_{2}$ & 6.3 & 4.0 \\
\hline
\end{tabular}

TABLE 3. - LIQUID-JET PHYSICAL PROPERTIES AT $20^{\circ} \mathrm{C}$ AND VALUES OF $K$ FOR EQ. (1)

\begin{tabular}{|l|c|c|c|c|c|}
\hline \multirow{3}{*}{ Liquid } & \multicolumn{3}{|c|}{ Physical properties } & \multicolumn{2}{c|}{$\begin{array}{c}\text { Values of } k \text { for } \\
\text { atomizing-gases }\end{array}$} \\
\cline { 2 - 4 } & $\begin{array}{l}\mu_{1} \times 10^{2} \\
\text { poises }\end{array}$ & $\begin{array}{c}\sigma \\
\text { dynes/cm }\end{array}$ & $\begin{array}{c}\rho_{1} \\
g / c c\end{array}$ & $N_{2}$ & He \\
\hline Water & 10.10 & 72.8 & 1.00 & $\mathrm{a}_{11.5}$ & $\mathrm{a} 86.5$ \\
JP-5 & 15.8 & 28.5 & .68 & $b_{12.7}$ & $b_{95.3}$ \\
n-Octane & 5.42 & 21.8 & .82 & $b_{24.2}$ & $b_{181.7}$ \\
\hline
\end{tabular}

aEperimental.

balculated.
11. Adelberg, M., "Mean Drop-Size Resulting from the Injection of a Liquid Jet Into a High-Speed Gas Stream, " AIAA Journal, Vol. 6. No. 6. June 1968, pp. 1143-1147.

12. Glasstone, S., Textbook of Physical Chemistry, D. Van Nostrand Co. Inc., New York, 2nd Edition, 1946, p. 253.

13. Mugele, R.A., and Evans. H.O, "Droplet Size Distribution in Sprays," Industrial and Engineering Chemistry, Voi. 43, No. 6, Juile 1951, pp. 1317-1324.

TABLE 2. - EFFECT OF PHYSICAL PROPERTIES ON RECIPROCAL SMO, AT MACH I GASFLOW

\begin{tabular}{|c|c|}
\hline Source & Relationship \\
\hline \multicolumn{2}{|r|}{ Gas-phase properties } \\
\hline $\begin{array}{l}\text { Present } \\
\text { study } \\
\text { Theory }\end{array}$ & $\begin{array}{l}D_{32}^{-1}-v_{c}^{1.33}, \rho_{g}^{1.33} \cdot \mu_{g}^{-0.75}, \mu_{g}^{-0.46}, v_{m}^{2.25} \\
D_{32}^{-1}-v_{g}^{1.33} \cdot \rho_{g}^{0.67}, \mu_{g}^{0}, \mu_{g}^{0}, v_{m}^{0}\end{array}$ \\
\hline \multicolumn{2}{|r|}{ Llquid-jet properties } \\
\hline $\begin{array}{r}\text { Present } \\
\text { study }\end{array}$ & $\begin{array}{l}D_{32}^{-1} \sim \rho_{1}^{0.31}, \mu_{1}^{-0.44}, \sigma^{-0.44} \\
D_{32}^{-1} \sim \rho_{1}^{0.33}, \mu_{1}^{0.67}, \sigma^{-0.33}\end{array}$ \\
\hline \multicolumn{2}{|r|}{ Other terms } \\
\hline $\begin{array}{l}\text { Present } \\
\text { study }\end{array}$ & $\begin{array}{l}0_{32}^{-1} \sim D_{0}^{-0.2} \cdot g^{-0.75} \\
0_{32}^{-1}-0_{0}^{0} \cdot g^{0}\end{array}$ \\
\hline
\end{tabular}

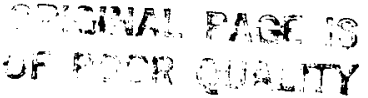




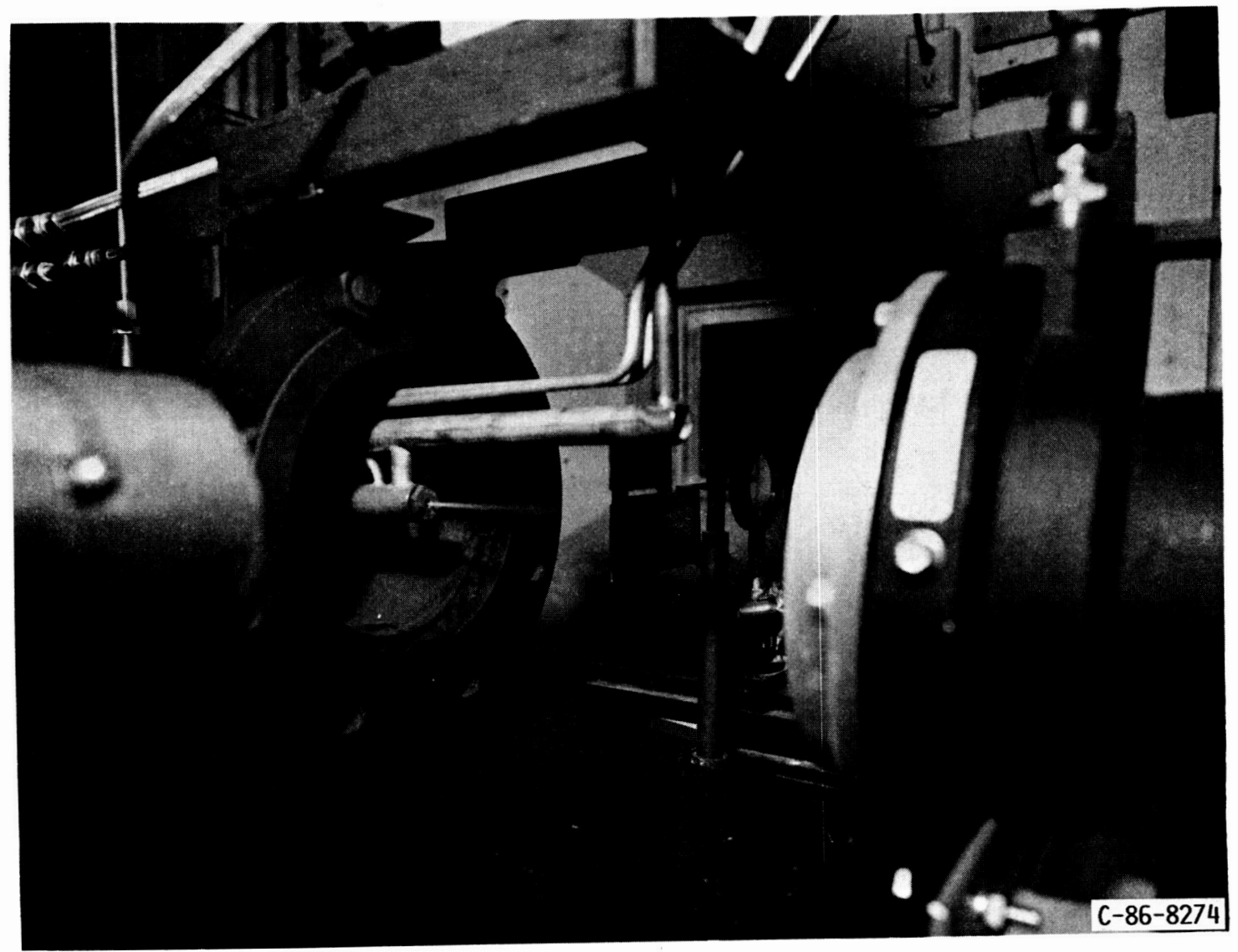

FIGURE 1. - APPARATUS AND AUXILLIARY EQUIPMENT.

ORIGNAL PAGE IS

OF POOR QUALITY 


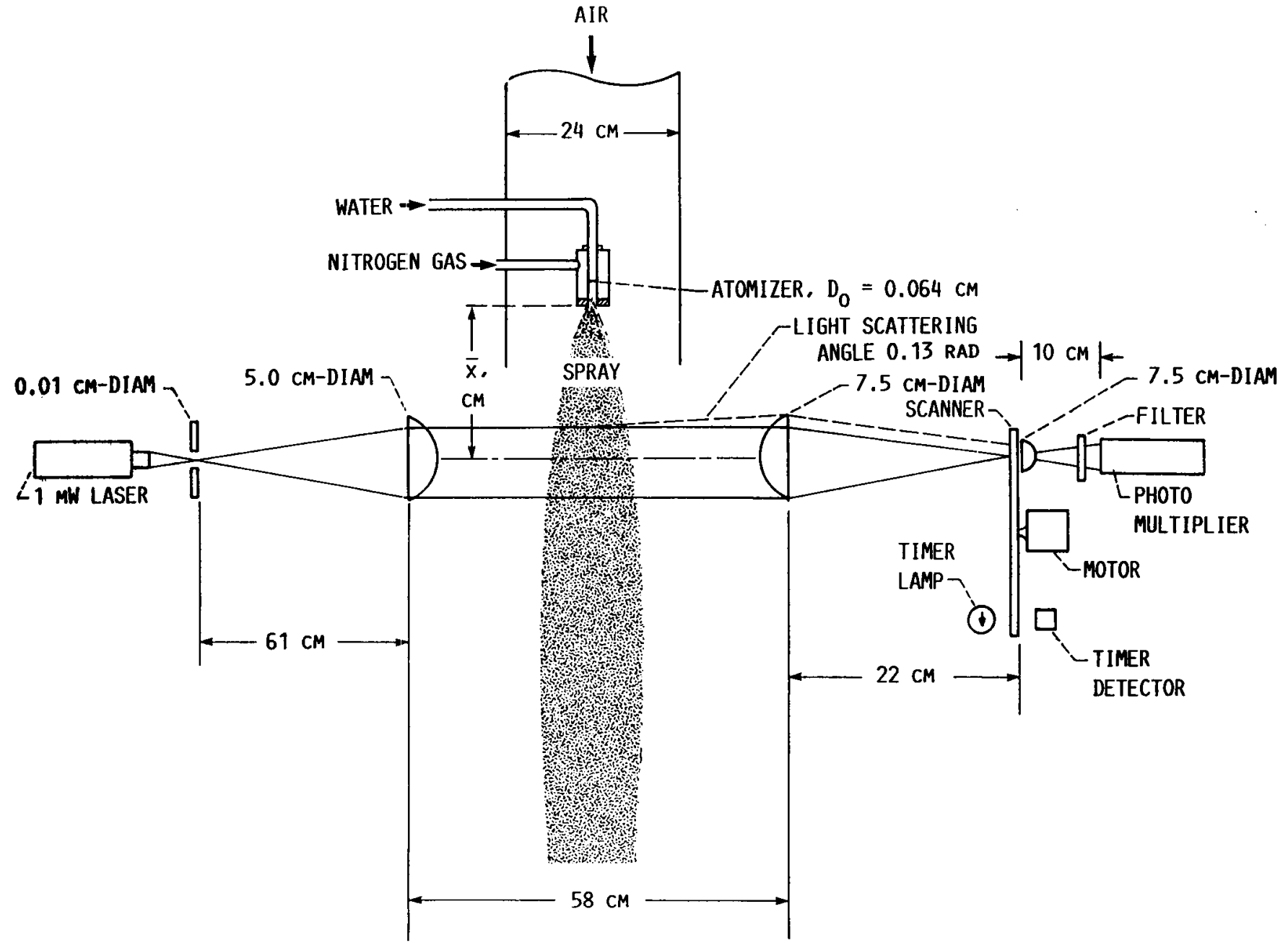

FIGURE 2. - ATMOSPHERIC PRESSURE TEST SECTION AND OPTICAL PATH OF SCATTERED-LIGHT SCANMER. 


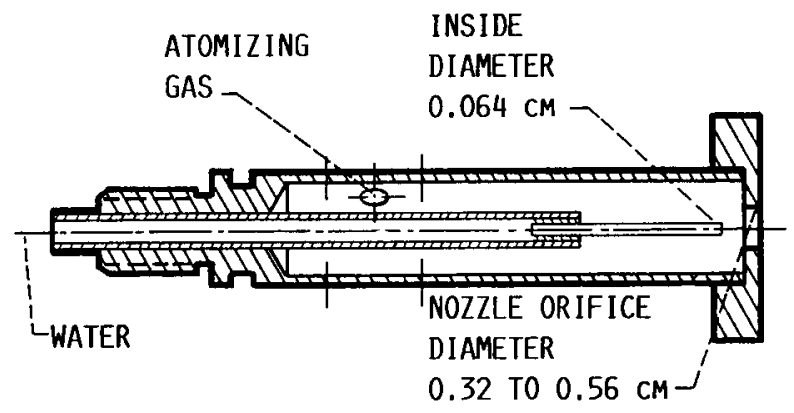

FIGURE 3. - DIAGRAM OF PNEUMATIC TWO-FLUID ATOMIZER.

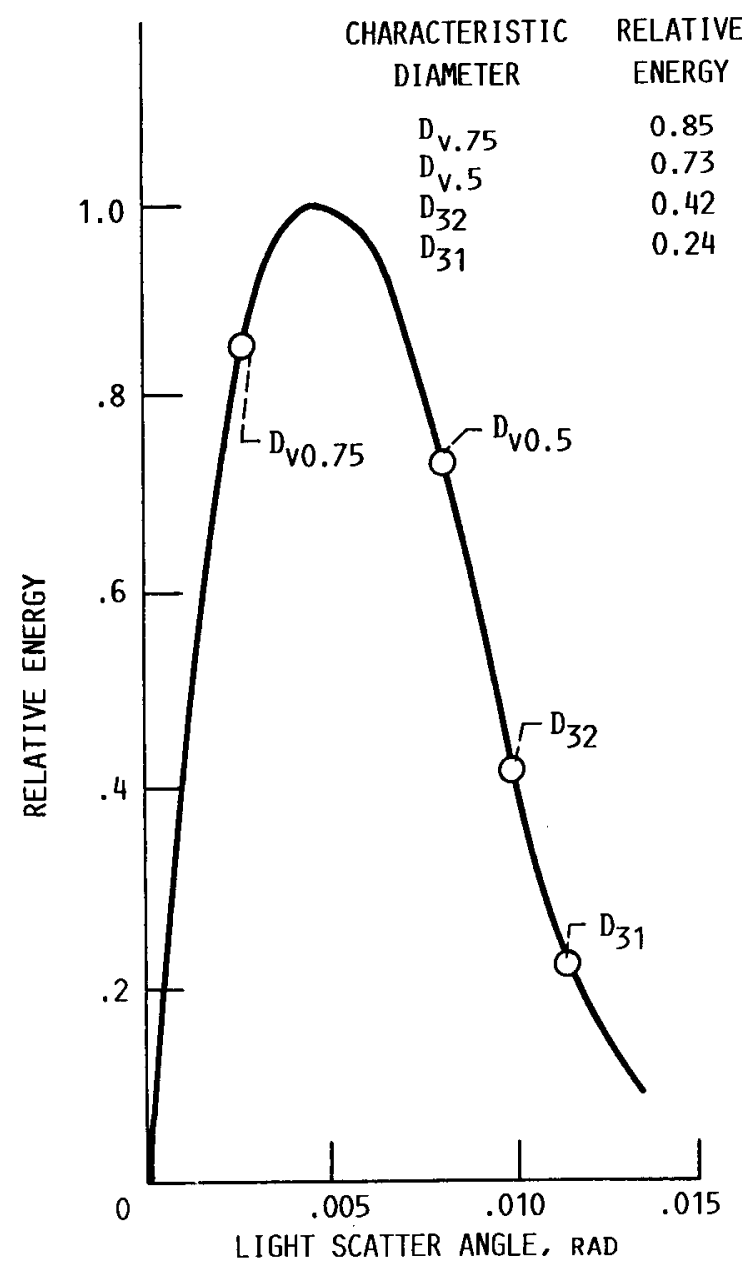

FIGURE 4. - TYPICAL SCATTERED-LIGHT ENERGY CURVE WITH FOUR CHARACTERISTIC DIAMETERS. 


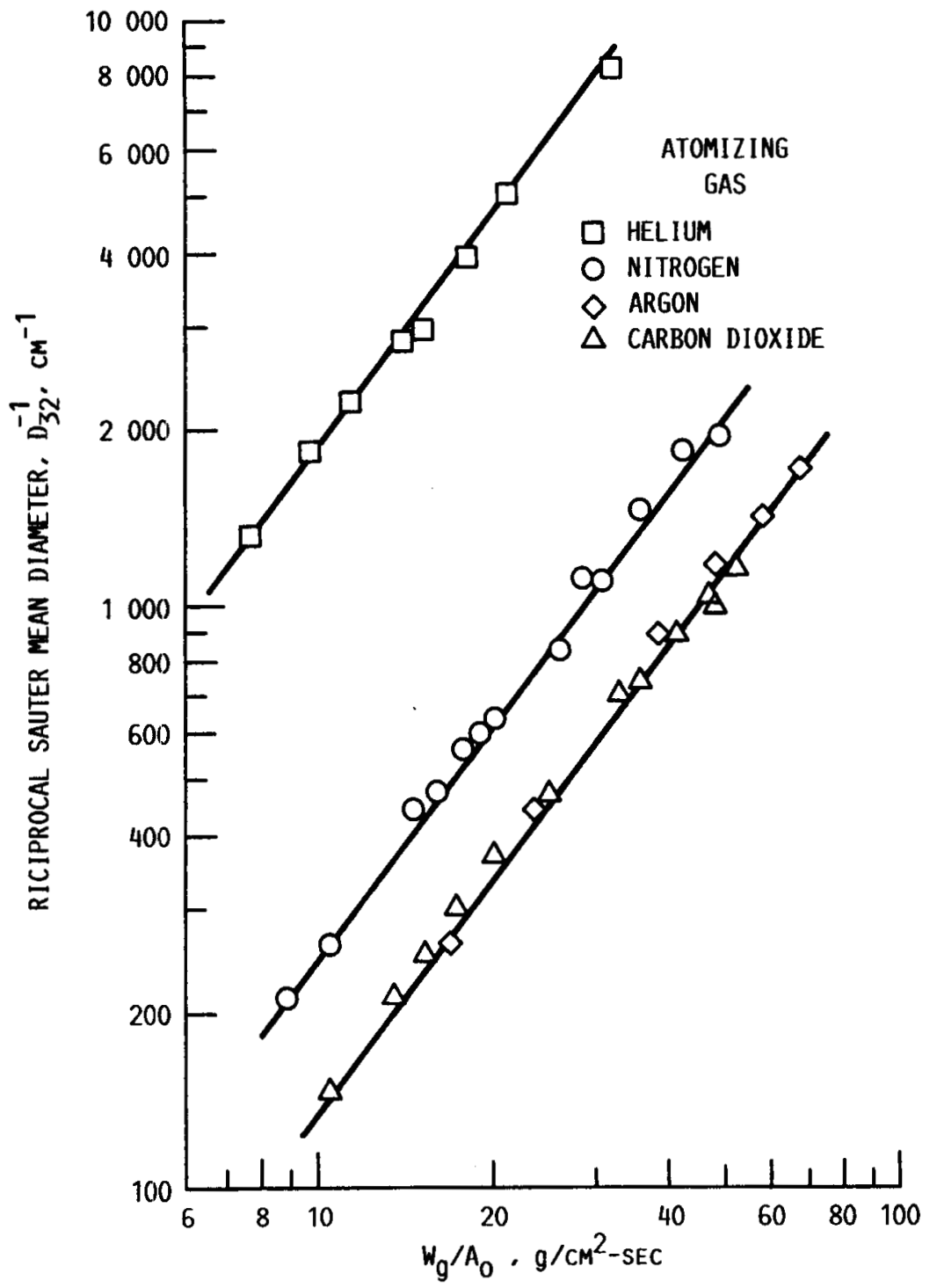

FIGURE 5. - VARIATION OF RECIPROCAL SAUTER MEAN DIAMETER WITH GAS FLOWRATE PER UNIT AREA, $W_{g} / A_{0}$. AT A LIQUID FLOWRATE OF $3.15 \mathrm{~g} / \mathrm{sEC}$. 


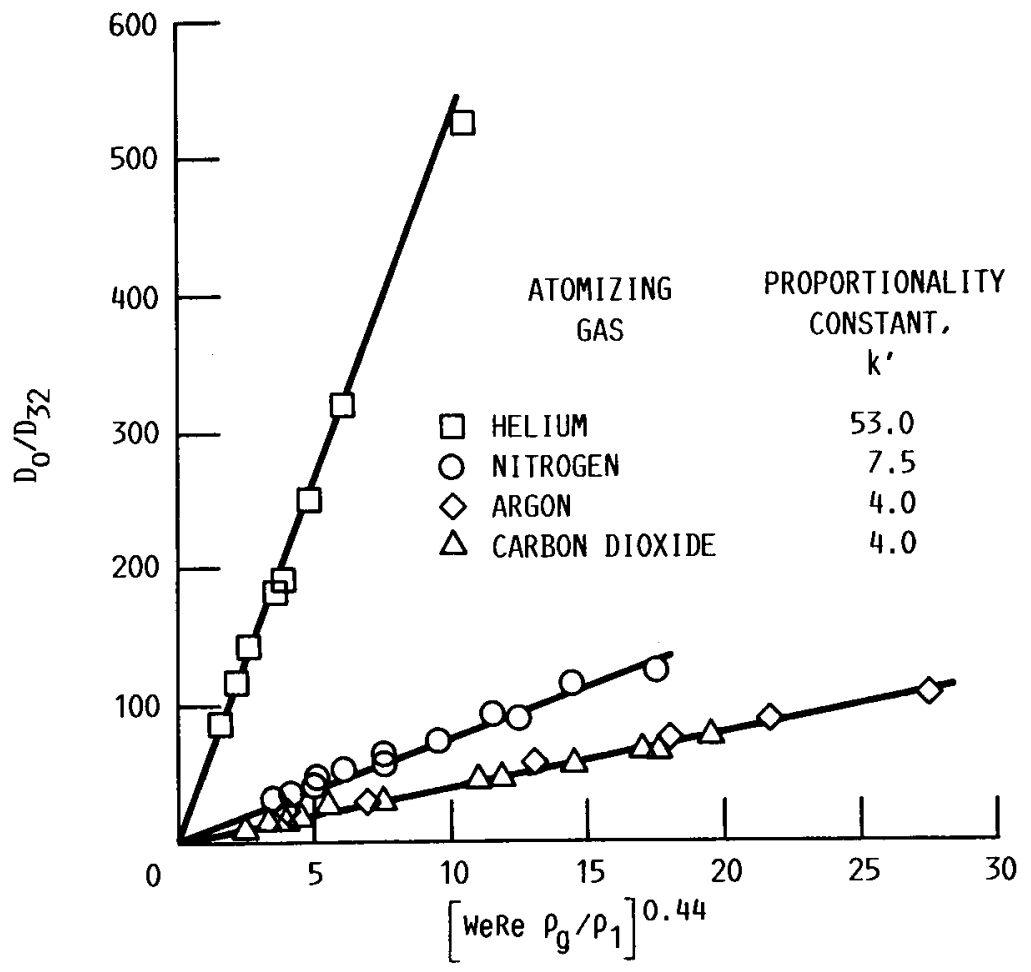

FIGURE 6. - CORRELATION OF SAUTER MEAN DIAMTER, $\mathrm{D}_{32}$ ' WITH DIMENSIONLESS GROUP WERE AND FLUID DENSITY RATIO.

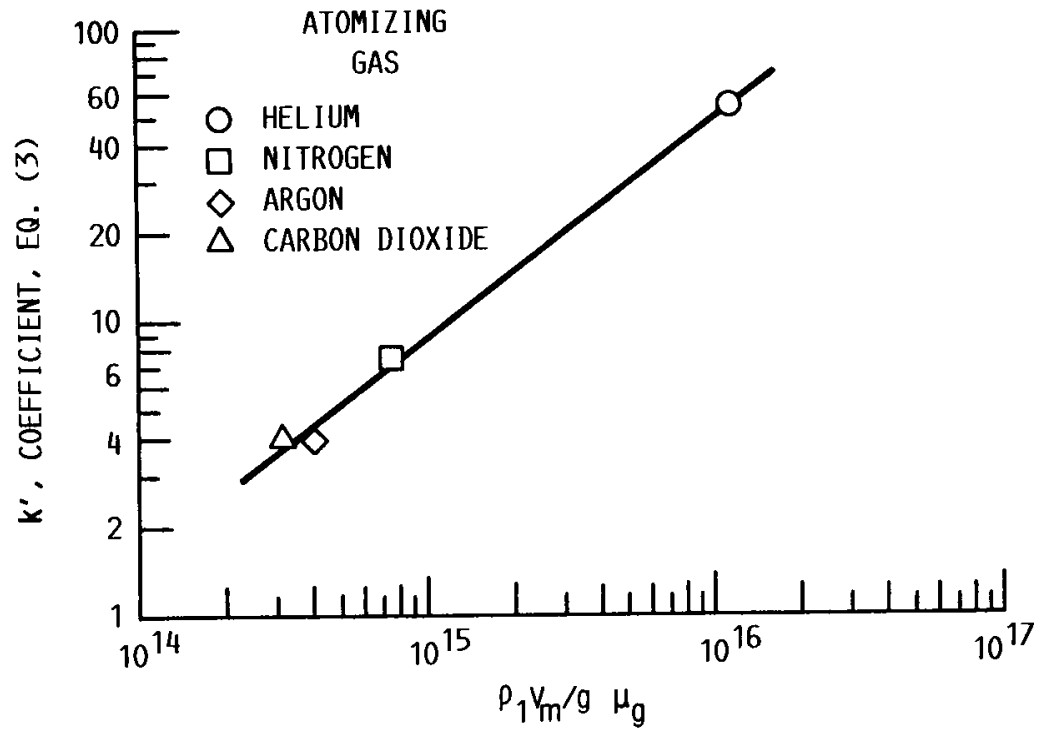

FIGURE 7. - CORRELATION OF PROPORTIONALITY COEFFICIENT $k$ ' WITH DIMENSIONLESS GROUP $\rho_{i} V_{m} / g \mu_{g}$. 


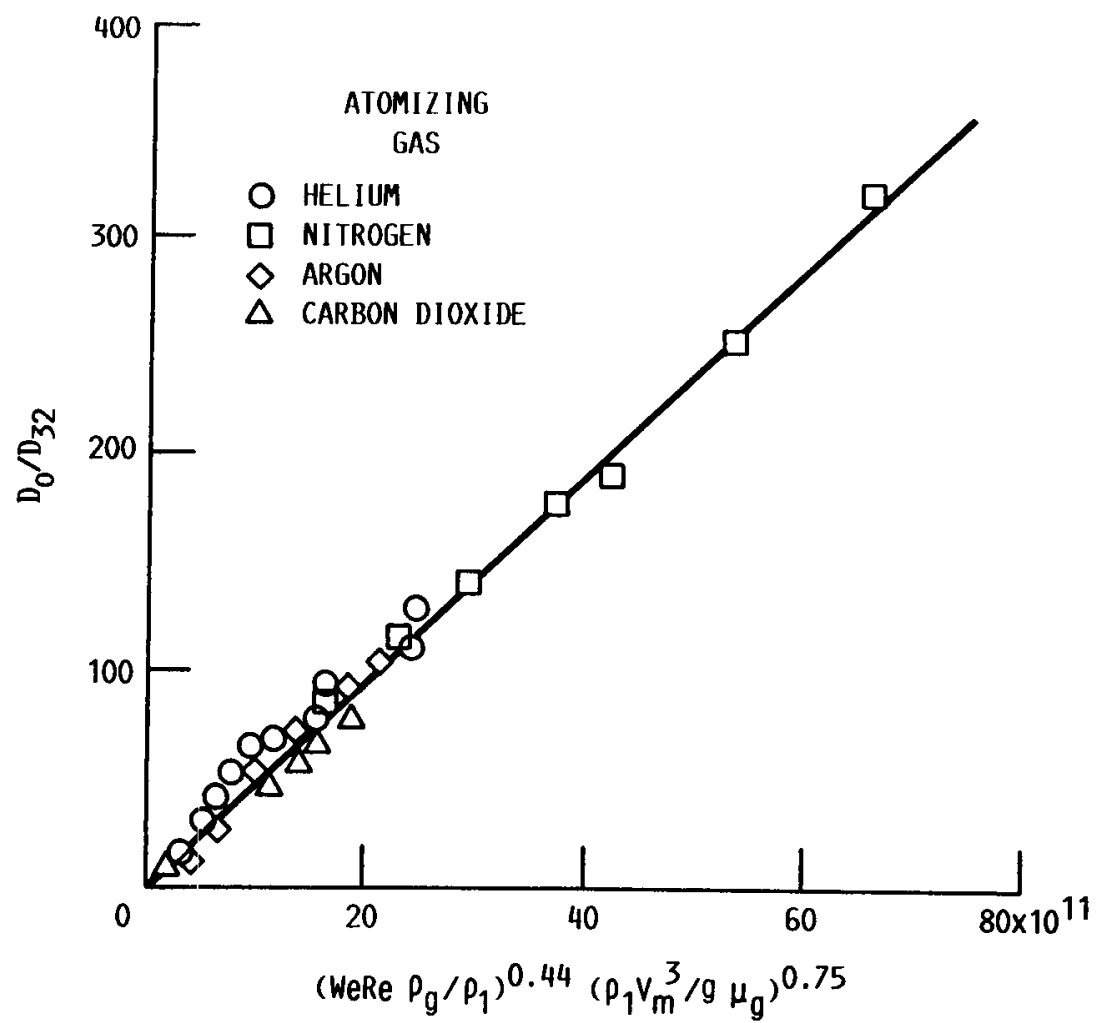

FIGURE 8. - CORRELATION OF NORMALIZED RECIPROCAL SAUTER MEAN DIAMETER WITH DIMENSIONLESS GROUPS.

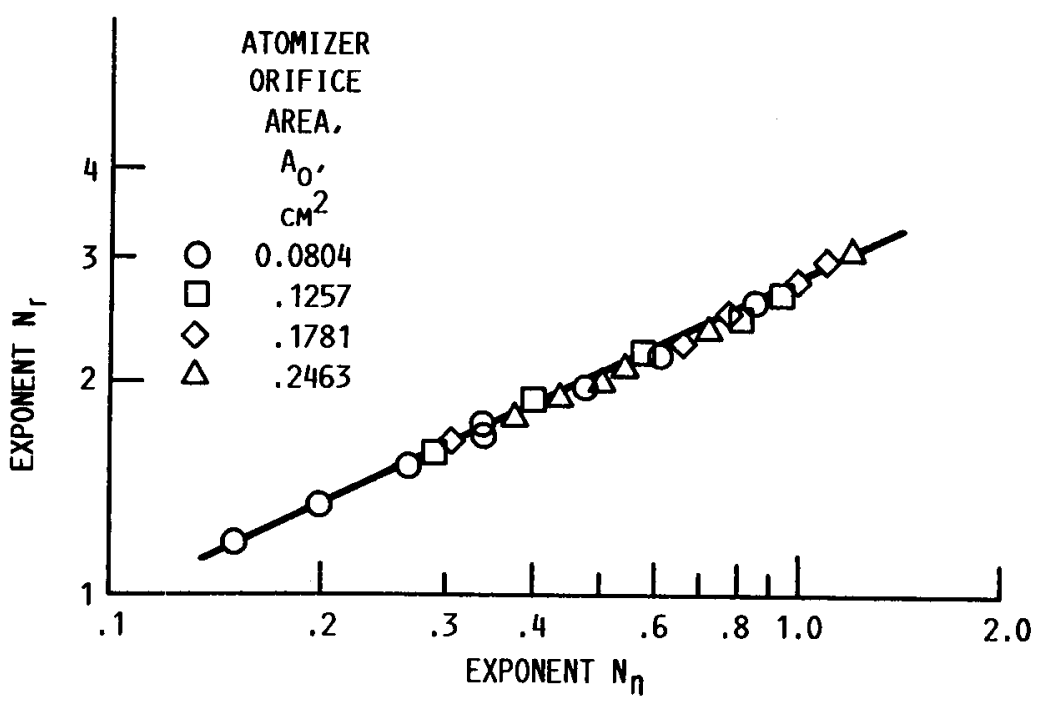

FIGURE 9. - CORRELATION OF ROSIN-RAMMLER AND NUKIYAMA TANASAWA EXPONENTS $N_{r}$ AND $N_{n}$, RESPECTIVELY. 


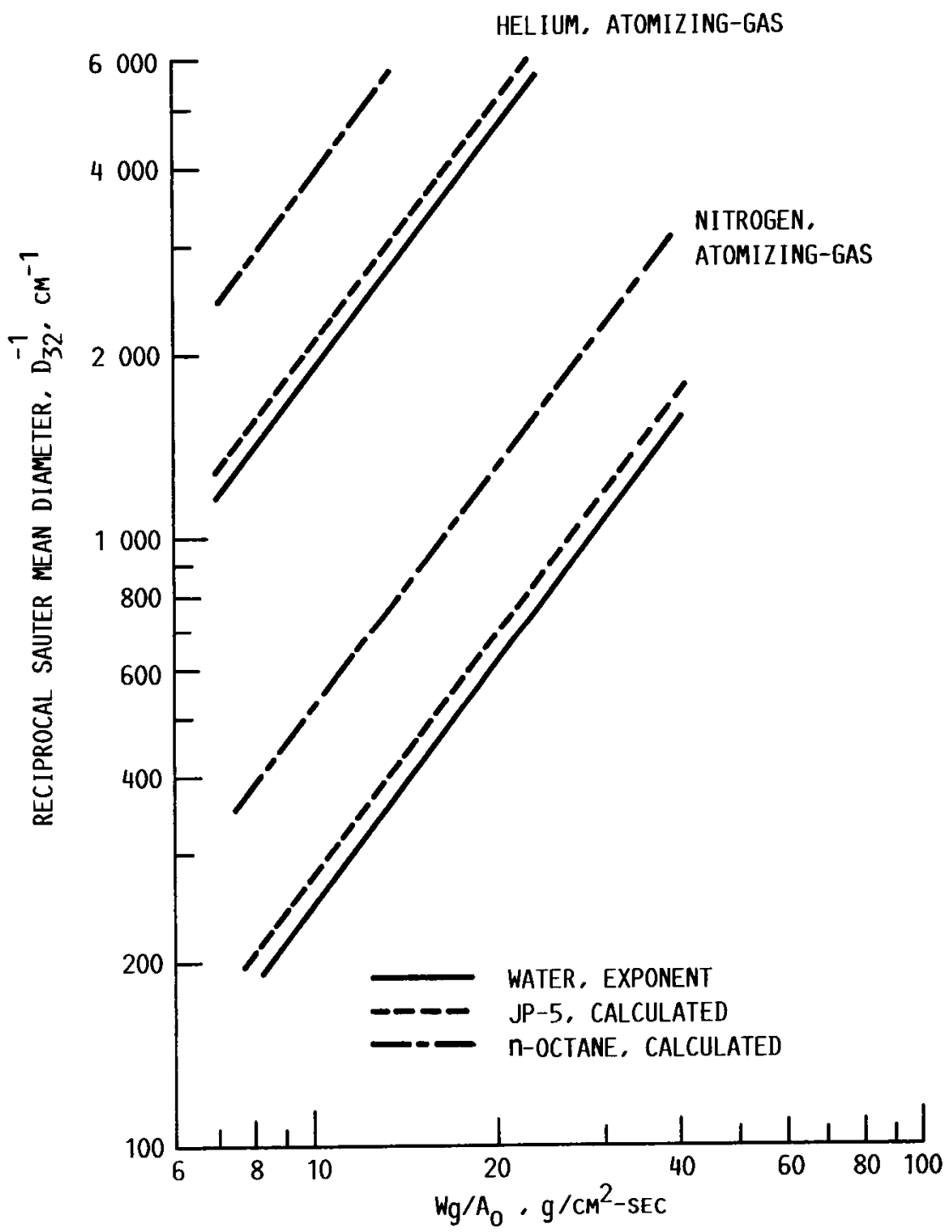

FIGURE 10. - COMPARISON OF RECIPROCAL SMD'S FOR WATER WITH FUEL-SPRAY CALCULATED VALUES 


\begin{tabular}{|c|c|c|c|c|}
\hline \multicolumn{5}{|c|}{ Report Documentation Page } \\
\hline $\begin{array}{l}\text { 1. Report No. } \\
\text { NASA TM-102013 }\end{array}$ & \multicolumn{2}{|c|}{ 2. Government Accession No. } & \multicolumn{2}{|c|}{ 3. Recipient's Catalog No. } \\
\hline \multirow{2}{*}{\multicolumn{3}{|c|}{$\begin{array}{l}\text { 4. Title and Subtitle } \\
\text { Gas Density Effect on Dropsize of Simulated Fuel Sprays }\end{array}$}} & \multirow{2}{*}{\multicolumn{2}{|c|}{ 5. Report Date }} \\
\hline & & & & \\
\hline & & & \multicolumn{2}{|c|}{ 6. Performing Organization Code } \\
\hline \multirow[t]{2}{*}{$\begin{array}{l}\text { 7. Author(s) } \\
\text { Robert D. Ingebo }\end{array}$} & & & \multicolumn{2}{|c|}{$\begin{array}{l}\text { 8. Performing Organization Report No. } \\
\text { E-4725 }\end{array}$} \\
\hline & & & \multicolumn{2}{|l|}{$\begin{array}{l}\text { 10. Work Unit No. } \\
505-62-21\end{array}$} \\
\hline \multirow{2}{*}{\multicolumn{3}{|c|}{$\begin{array}{l}\text { 9. Performing Organization Name and Address } \\
\text { National Aeronautics and Space Administration } \\
\text { Lewis Research Center } \\
\text { Cleveland, Ohio } 44135-3191\end{array}$}} & \multicolumn{2}{|c|}{ 11. Contract or Grant No. } \\
\hline & & & \multirow{2}{*}{\multicolumn{2}{|c|}{$\begin{array}{l}\text { 13. Type of Report and Period Covered } \\
\text { Technical Memorandum }\end{array}$}} \\
\hline \multirow{2}{*}{\multicolumn{3}{|c|}{$\begin{array}{l}\text { 12. Sponsoring Agency Name and Address } \\
\text { National Aeronautics and Space Administration } \\
\text { Washington, D.C. 20546-0001 }\end{array}$}} & & \\
\hline & & & \multicolumn{2}{|c|}{ 14. Sponsoring Agency Code } \\
\hline \multicolumn{5}{|l|}{$\begin{array}{l}\text { 15. Supplementary Notes } \\
\text { Prepared for the 25th Jc } \\
\text { Monterey, California, J }\end{array}$} \\
\hline \multicolumn{5}{|l|}{ 16. Abstract } \\
\hline \multicolumn{5}{|c|}{$\begin{array}{l}\text { Two-phase flow in pneumatic two-fluid fuel nozzles was experimentally investigated to deter } \\
\text { atomizing-gas density and gas mass-flux on liquid-jet breakup in sonic-velocity gasflow. Dro } \\
\text { obtained for the following atomizing-gases: nitrogen, argon, carbon dioxide and helium. The } \\
\text { cover a gas molecular-weight range of } 4 \text { to } 44 \text {. Atomizing-gas max-flux ranged from } 6 \text { to } 50 \\
\text { differently sized two-fluid fuel nozzles were used having orifice diameters that varied from } 0 \\
\text { ratio of liquid-jet diameter to } \mathrm{SMD}, \mathrm{D}_{\mathrm{o}} / \mathrm{D}_{32} \text {, was correlated with aerodynamic and liquid-sur } \\
\text { the product of the Weber and Reynolds number, WeRe, and gas-to-liquid density ratio, } \rho_{\mathrm{g}} / \rho_{1} \\
\text { dropsize with breakup forces produced by using different atomizing-gases, a new molecular-s } \\
\text { group was derived, } \rho_{1} \mathrm{~V}_{\mathrm{m}}^{3} / \mathrm{g} \mu_{\mathrm{g}} \text {, and used to obtain the following expression: }\end{array}$} \\
\hline \multicolumn{2}{|c|}{ 17. Key Words (Suggested by Author(s)) } & \multirow{2}{*}{\multicolumn{3}{|c|}{$\begin{array}{l}\text { 18. Distribution Statement } \\
\text { Unclassified-Unlimited } \\
\text { Subject Category } 34\end{array}$}} \\
\hline $\begin{array}{l}\text { Liquid fuel sprays; Atomi } \\
\text { Mean dropsize; Multi-pha }\end{array}$ & 1 jet; Fuel nozzles; & & & \\
\hline $\begin{array}{l}\text { 19. Security Classif. (of this report) } \\
\text { Unclassified }\end{array}$ & $\begin{array}{l}\text { 20. Security Classif. (o } \\
\text { Uncla }\end{array}$ & $\begin{array}{l}\text { this page) } \\
\text { assified }\end{array}$ & $\begin{array}{c}\text { 21. No of pages } \\
14\end{array}$ & $\begin{array}{r}\text { 22. Price* } \\
\mathrm{A} 03\end{array}$ \\
\hline
\end{tabular}

